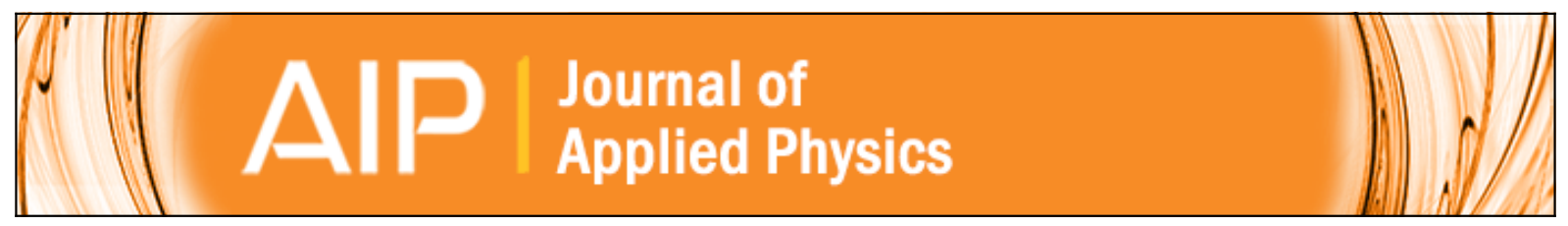

Compositional and magnetic properties of iron nitride thin films

D. H. Mosca, P. H. Dionisio, W. H. Schreiner, I. J. R. Baumvol, and C. Achete

Citation: Journal of Applied Physics 67, 7514 (1990); doi: 10.1063/1.345812

View online: http://dx.doi.org/10.1063/1.345812

View Table of Contents: http://scitation.aip.org/content/aip/journal/jap/67/12?ver=pdfcov

Published by the AIP Publishing

Allp Re-register for Table of Content Alerts

Create a profile.

Sign up today! 


\title{
Compositional and magnetic properties of iron nitride thin films
}

\author{
D. H. Mosca, P. H. Dionisio, W. H. Schreiner, and I. J. R. Baumvol \\ Instituto de Fisica-UFRGS, 91500 Porto Alegre, RS, Brasil \\ C. Achete \\ Laboratório de Estudos de Materiais e Interfaces, COPPE-UFRJ, 68504 Rio de Janeiro, RJ, Brasil
}

(Received 4 December 1989; accepted for publication 22 February 1990)

\begin{abstract}
The compositional and magnetic properties of iron-nitride thin films deposited by dc reactive magnetron sputtering under various nitrogen partial pressure conditions have been investigated by x-ray diffraction, Mössbauer and Auger electron spectroscopy as well as magnetic measurements. The $x$-ray diffraction patterns indicate a mixed phase composition.

${ }^{57}$ Fe Mössbauer spectroscopy shows that part of the nitrogen atoms are randomly distributed on interstitial sites with the formation of nonstoichiometric compounds. The excessive width of the Mössbauer lines indicates the degree of disorder of the different iron nitride precipitates. The nitrogen concentration as a function of depth is obtained by sputter-etched Auger electron spectroscopy. Furthermore, the ferromagnetic films show moderate saturation magnetization and coercivities at room temperature as compared with pure iron thin films.
\end{abstract}

\section{INTRODUETION}

The iron-nitrogen system has been studied for many decades due to the remarkable mechanical and magnetic properties of this system. Much attention has also been given to the electronic structure of the interstitial compounds of iron and other transition metal nitrides. ${ }^{1-6}$ These reports focused on the electronic structure and compositional effects of the tempering process. The initial interest in the Fe-N system came from the nitriding of steels to improve the abrasive strength by surface hardening. The nature of the hardening process proved to be associated with the capture of nitrogen atoms by disiocations, vacancies, and precipitates. 7,8

Recently, the magnetic properties of iron-nitride thin fims were reported ${ }^{9-17}$ and appeared to have both scientific and technological interest. Many authors ${ }^{11-15}$ have suggested that iron nitride compounds have potential applications as magnetic recording heads and media.

Iron and nitrogen in bulk form three metastable compounds which are stabie at room temperature: $\mathrm{Fe}_{8} \mathrm{~N}, \mathrm{Fe}_{4} \mathrm{~N}$, and $\mathrm{Fe}_{2} \mathrm{~N}^{18}$ Ferromagnetic iron nitride compounds ( $\mathrm{Fe}_{x} \mathrm{~N}$ with $2<x \leqslant 8$ ) have high mechanical hardness and large saturation magnetization, even higher than pure iron. "The chemical stability is also much superior to that of the pure metal. ${ }^{12}$

This paper reports on detailed investigations of structural, compositional, and magnetic properties of the iron nitride thin films as deposited by dc reactive magnetron sputtering. Section II describes the experimental procedures for film deposition and characterization. The results are shown in Sec. III and the discussion and conclusions in Sec. IV.

\section{EXPERMMENT}

The iron-nitride films were deposited in a planar magnetron sputtering system. The sample holder is within $4 \mathrm{~cm}$ from the target (Fe 99.97 at \%). The vacuum chamber has a base pressure of $1 \times 10^{-6}$ Torr. The total pressure of the gases introduced was kept at $4 \times 10^{-4}$ Torr by controlling the gas-fiow rate. Pure argon ( $99.997 \%$ ) and pure nitrogen
(99.995\%) gases were used as sputtering gases. A negative voltage of $500 \mathrm{~V}$ was applied to the target, while the substrates were kept at ground potential. Silicon wafers (111) were used as substrates and the deposition temperature did not exceed $60^{\circ} \mathrm{C}$ during fim growth. The preparation conditions and deposition rates are shown in Table $\mathrm{I}$.

The film thickness and deposition rates were determined with $2-\mathrm{MeV} \alpha$-particle Rutherford backscattering spectroscopy (RBS). The conversion electron Mössbauer spectroscopy (CEMS) measurements were made using a ${ }^{57} \mathrm{Co}$ source dissolved in a $\mathrm{Rh}$ matrix with an activity of 50 $\mathrm{mCi}$. The sample was placed in a gas-fow proportional counter where $7.3-\mathrm{keV}$ conversion electron resulting from recoilless ${ }^{57}$ Fe nuclei within the sample were detected in a backscattering geomtry.

$X$-ray difraction was used for structural analysis. The composition of the films as a function of depth was determined by means of sputtered Auger electron spectroscopy (AES), using an argon-ion gun.

The static magnetic properties of specially prepared disklike films were studied using a vibrating sample magnetometer (VSM) in magnetic fields up to $5 \mathrm{kOe}$ applied in the plane of the films. The saturation magnetization per unit iron weight is estimated from the amount of iron in the films as obtained by $\mathrm{RBS}$.

\section{RESULTS}

\section{A. Crystal structures}

Figure 1 shows the $x$-ray diffraction patterns for the four samples. Figure 1 (a), corresponding to the pure iron film (nitrogen partial pressure $P_{\mathrm{N}_{2}}=0$ Torr), shows only two of the principal diffaction lines of $\alpha$ iron. This indicates a preferential orientation of the crystallites in the film. This preferential orientation of the growth of the grains is also observed in the other samples.

Figure $1(b)$ shows the diffraction pattern of sample $B$ $\left(P_{\mathrm{N}_{2}}=4 \times 10^{-6}\right.$ Torr $)$. This figure shows a diffraction line corresponding to the (110) refiection of $\alpha$-iron with a large broadening towards high angles. Although unexpected, this 
TABLE I. Parameters of the de reactive sputtering deposition of the Fe-N thin films.

\begin{tabular}{|c|c|c|c|c|}
\hline Sample & $\begin{array}{c}\text { Deposition time } \\
t(\min )\end{array}$ & $\begin{array}{c}\mathrm{N}_{z} \text { Partial Pressure } \\
P_{N_{2}} \text { (Torr) }\end{array}$ & $\begin{array}{c}\text { Fim thickness } \\
d(\AA)\end{array}$ & $\begin{array}{c}\text { Deposition rate } \\
Y(\AA) / s)\end{array}$ \\
\hline A & 20 & 0 & 5100 & 4.3 \\
\hline $\mathrm{B}$ & 20 & $4 \times 10^{-6}$ & 3500 & 2.9 \\
\hline C & 21 & $3 \times 10^{-5}$ & 2700 & 2.2 \\
\hline $\mathrm{D}$ & 24 & $3 \times 10^{-4}$ & 3300 & 2.3 \\
\hline
\end{tabular}

strong (110) texture of Fe that is observed here when $\mathrm{Fe}$ films are deposited on (111) Si substrates seems to be a common feature for the growing of vacuum deposited Fe films. We have previously observed the same (110) texture for $\mathrm{Fe}$ films deposited by electron-beam evaporation on oxidized silicon substrates. ${ }^{18,19}$ Besides, we identify the (101) reflection of the $\varepsilon-\left(\mathrm{Fe}_{2} \mathrm{~N}-\mathrm{Fe}_{3} \mathrm{~N}\right)$ structure. Around $2 \theta \cong 41^{\circ}$ appears another broad diffraction line which cannot be unequivocally associated with a particular Fe-N compound. It can be associated with the $(002)$ refiection of the $\varepsilon-\left(\mathrm{Fe}_{2} \mathrm{~N}\right.$. $\mathrm{Fe}_{3} \mathrm{~N}$ ) and $\mathrm{or} \varepsilon-\mathrm{Fe} \mathrm{e}_{3} \mathrm{~N}$ or yet with the (111) reflection of the $\mathrm{Fe}_{4} \mathrm{~N}$. In this same figure the $\mathrm{x}$-ray diffraction line corresponding to the (311) reflection of $\zeta-\mathrm{Fe}_{2} \mathrm{~N}$ is identified.

Figure $1(\mathrm{c})$ shows the $\mathrm{x}$-ray diffraction spectrum of sample $C\left(B_{\mathrm{N}_{2}}=3 \times 10^{-5}\right.$ Torr $)$. This pattern shows a salient diffraction line identified as the (101) reflection of $\varepsilon$ $\mathrm{Fe}_{3} \mathrm{~N}$. Two X-ray lines associated with the (002) and (212) reffections of $\xi-\mathrm{Fe}_{2} \mathrm{~N}$ are also visible in Fig. $1(\mathrm{c})$.

Figure $1(d)$ shows the difraction spectrum of sample D $\left(P_{\mathrm{N}_{2}}=3 \times 10^{-4}\right.$ Torr. We identify the (211) reflection of the $\zeta-F_{2} \mathbb{N}$ compound. The other diffraction line can be associated with the (311) reflection of $\zeta-\mathrm{Fe}_{2} \mathrm{~N}$ and/or with (102) reflection of $\varepsilon-F e_{3} N$.

\section{B. Auger electron spectroscopy}

Figure 2 exhibits the AES spectrum of sample $C$ ( $P_{\mathrm{N}}$ $=3 \times 10^{-5}$ Torr). This spectrum is typical of the iron nitride samples. It presents the characteristic signal of iron together with the peaks of oxygen, nitrogen, carbon, and argon after 16 min of sputter etching. We observe some contamination of the film by oxygen and carbon.

A quantitative analysis of sample $B\left(P_{\mathrm{N}_{2}}=4 \times 10^{-6}\right.$ Torr) shows an average atomic concentration near the outermost surface of $88.65 \pm 0.25 \%$ Fe and $11.35 \pm 0.25 \% \mathrm{~N}$, i.e., $\mathrm{Fe}_{7.81} \mathrm{~N}$. Sample $\mathrm{C}\left(P_{\mathrm{N}}=3 \times 10^{-5}\right.$ Torr $)$ shows an average atomic concentration of $77.65 \pm 0.55 \% \mathrm{Fe}$ and $22.250 .50 \% \mathrm{~N}$, i.e., $\mathrm{Fe}_{3.49} \mathrm{~N}$. Finally, sample $\mathrm{D}\left(\boldsymbol{P}_{\mathrm{N},}\right.$ $=3 \times 10^{-4}$ Torr) shows the average atomic concentration of $66.30 \pm 0.10 \% \mathrm{Fe}$ and $33.60 \pm 0.20 \% \mathrm{~N}$, i.e., $\mathrm{Fe}_{1.97} \mathrm{~N}$. As can be seen, the nitrogen content incorporated in the fim structure during the deposition process is proportional to the $\mathrm{N}_{2}$ partial pressure on a nearly logarithmic scale.

The depth profile of the concentration of the species in the film, measured by the change in the Auger peak intensities versus sputter-etching time, shows an almost uniform nitrogen content along the thickness of the film below the

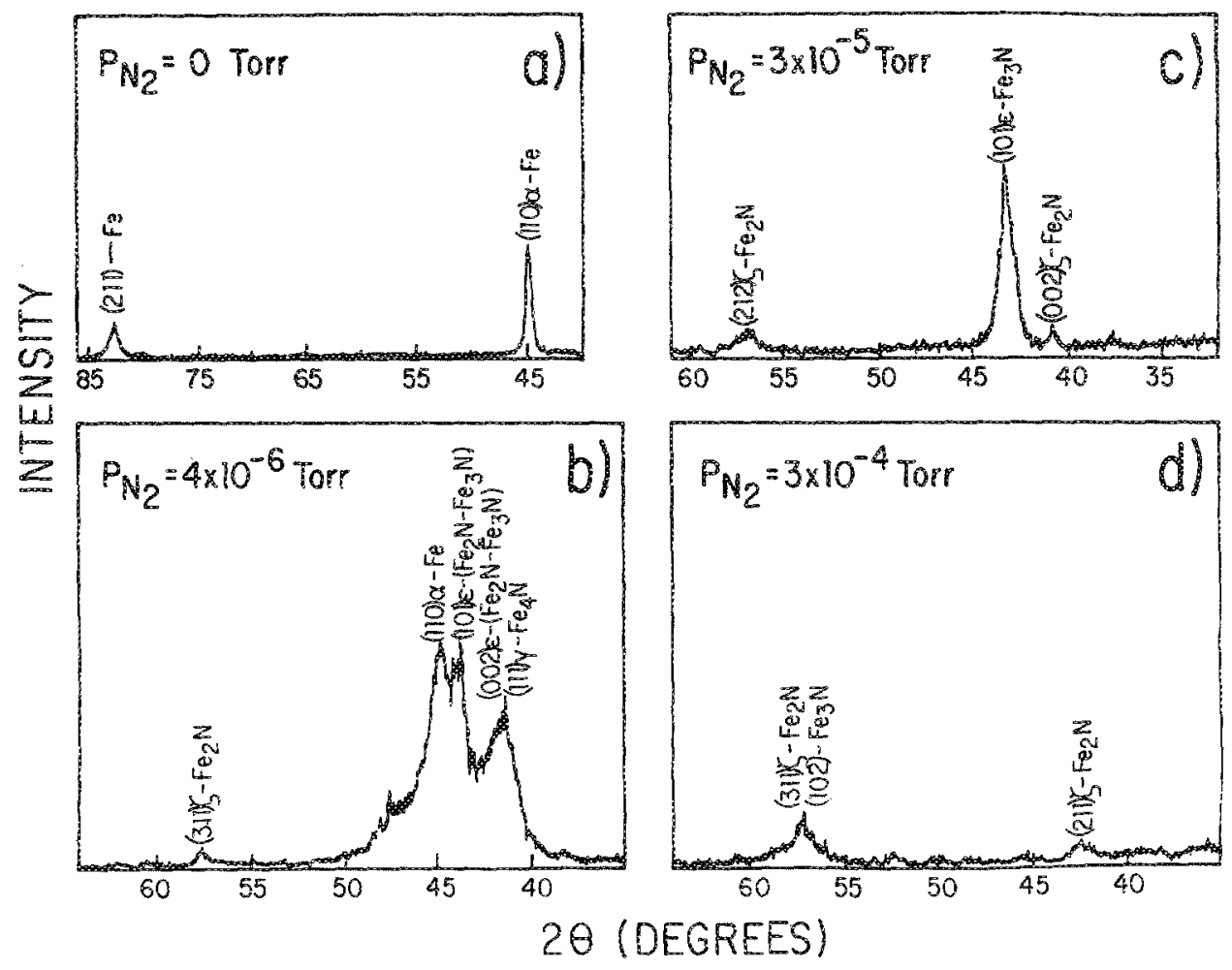

FIG. 1. X-ray diffraction diagrams of the samples preparcd in different $\mathrm{N}$. partial pressure, $P_{\mathrm{N}}$. 


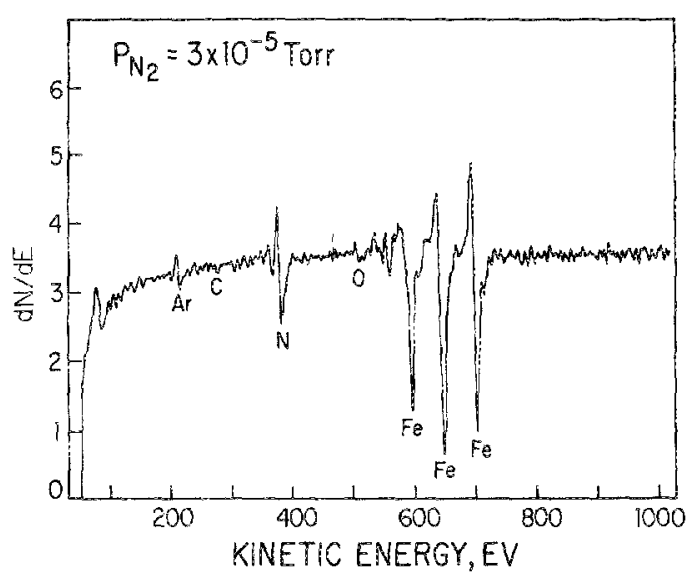

FIG. 2. Auger electron spectroseopy spectrum (using etching with argon ions during $16 \mathrm{~min})$ showing the elements in sample $\mathrm{C}\left(P_{\mathrm{N}_{z}}=3 \times 10^{-5}\right.$ Torr).

surface layers. In Fig. 3 we show the concentration versus depth profiles for sample $C$.

\section{Mossbauer datta}

Figure 4 shows the CEMS spectra of the four thin-fim samples. As it has been previously demonstrated ${ }^{20}$ the CEMS technique inspects a maximum depth of $2000 \AA$ below the surface, with about $50 \%$ of the conversion electrons that emerge from the sample surface coming from the first $500 \AA$. The inspection depth of the sputter-etching Auger spectroscopy was larger than this. The results of the two different analytical techniques do not compare very well, because the relative $F e / N$ concentrations measured by sputter-etched Auger do not correspond necessarily to the phases observed by CEMS in samples B and C. Figure 4(a) displays the spectrum obtained from the metallic pure iron fim $\left(\boldsymbol{P}_{\mathrm{N}}=0\right.$ Torr $)$. This is a normal six-line $\alpha$-iron spectrum with modified intensity ratios. The ratio of intensities of the lines is approximately $3: 3: 1$, different from bulk Mösbauer transmission results. The intensities of the Mossbatier lines are associated with the texture of the material.

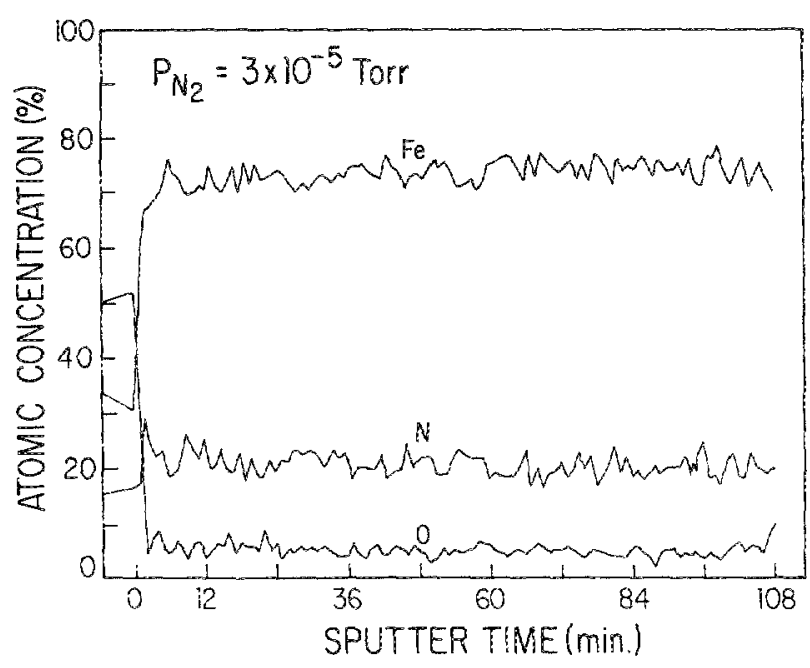

FIG. 3. Sputtered Auger electron spectroscopy profile of sample C.
Figure $4(b)$ shows the spectrum for sample $B\left(p_{N_{2}}\right.$ $=4 \times 10^{-6}$ Torr). The main contribution to the spectrum consists of the sextel of metallic pure iron. The Mösbauer linewidths are, however, much larger than those reported in the literature for pure iron, apparenty due to a spreading in the magnitude of the magnetic hyperfine fields. This is interpreted as a large disorder in the occupation of the interstitial sites by nitrogen atoms. This part of the spectrum is characteristic of the iron-nitrogen solid solutions. ${ }^{5}$ Besides, the spectrum reveals the presence of a contribution from another unidentified ferromagnetic compound. The fitting of this part of the spectrum was not possible.

Figure $4(c)$ shows the very complex spectrum obtained for sample $C$ ( $P_{\mathrm{N}_{2}}=3 \times 10^{\cdots 5}$ Torr $)$. We fitted the ferromagnetic part of this spectrum with four magnetic fields $(265,208,180$, and $78 \mathrm{kOe})$ which are interpreted as representative of nonstoichiometric $\mathrm{Fe}_{x} \mathrm{~N}(2<x<3)$-like precipitates. ${ }^{21}$ The nonmagnetic part of the spectrum displays two rather wide lines which can be decomposed into two doublets $\left(\Delta E_{Q}=1.00 \mathrm{mms}^{-1} . \delta=0.26 \mathrm{mms}^{-1}\right.$ and $\Delta E_{Q}=0.46$ mms $^{-1}, \delta=0.30$ mms $^{-1}$ ). We interpret these doublets as $\mathrm{Fe}_{2} \mathrm{~N}$ environments deficient in nitrogen atoms.

Figure 4 (d) shows the CEMS spectrum for sample D $\left(P_{\mathrm{N}_{2}}=3 \times 10^{-4}\right.$ Torr). As can be seen, this spectrum has a doublet which is identified as the Mossbauer spectrum of $\mathrm{Fe}_{2} \mathrm{~N}$ with $\delta=0.33 \mathrm{mms}^{-1}$ and $\Delta E_{Q}=0.25 \mathrm{mms}^{-1.22} \mathrm{Be}$ sides, we identify another doublet which is associated with $\gamma$ austenite structure. However, it is important to emphasize that the linewidth of the $\mathrm{Fe}_{2} \mathrm{~N}$ doublet is broadened and that the presence of the singlet of $\gamma$-austenite is negligible here. This is indicative of iron atoms of a given first-neighbor configuration (most probably $\mathrm{Fe}_{2} \mathrm{~N}$ ) having a variety of configurations of nitrogen atoms $\left(\mathrm{Fe}_{2+x} \mathrm{~N}\right.$ with $0<x<1$ ) as second and greater neighbors, suggesting deficiencies in the nitrogen content accommodated in an $\mathrm{Fe}_{2} \mathrm{~N}$ environment together with nitrogen in solid solution in a $\gamma$-austenite structure.

The Mössbauer parameters obtained from the fitting of all CEMS spectra are given in Table $\mathbf{I}$.

\section{Magnetic measurements}

It is known that all nitrides with the composition of $\mathrm{Fe}_{x} \mathrm{~N}$ with $x>3$ are ferromagnetic at room temperature. ${ }^{13}$ Figure 5 (a) shows the in-plane hysteresis loop of sample $A$ (pure iron film). In Fig. 5(b) we present the internal part of the hysteresis loop of Fig. 5(a) where we obtain a coercivity of 78 Oe. Figure 6 shows the in-plane hysteresis loops of samples $\mathrm{B}\left(P_{\mathrm{N}_{\mathrm{r}}}=4 \times 10^{-6}\right.$ Torr $)$ and $\mathrm{C}\left(P_{\mathrm{N},}=3 \times 10^{-5}\right.$ Torr) as measured by VSM at room temperature, respectively. According to Figs. 6(a) and 6(b) the saturation magnetizations of samples $B$ and $C$ are similar, being smaller than the saturation magnetization of the pure iron film. As can be seen from the $x$-ray and Mössbauer data, the smaller magnetizations of samples $B$ and $C$ result, in part, from the existence of paramagnetic phases in coexistence with the ferromagnetic phase. $X$-ray and CEMS analyses indicate the paramagnetic phase $\mathrm{Fe}_{2} \mathrm{~N}$ in both samples.

The coercivity of sample $B$ is 33 Oe, while sample $C$ has a coercivity of $360 \mathrm{e}$. These coercivities are small compared 


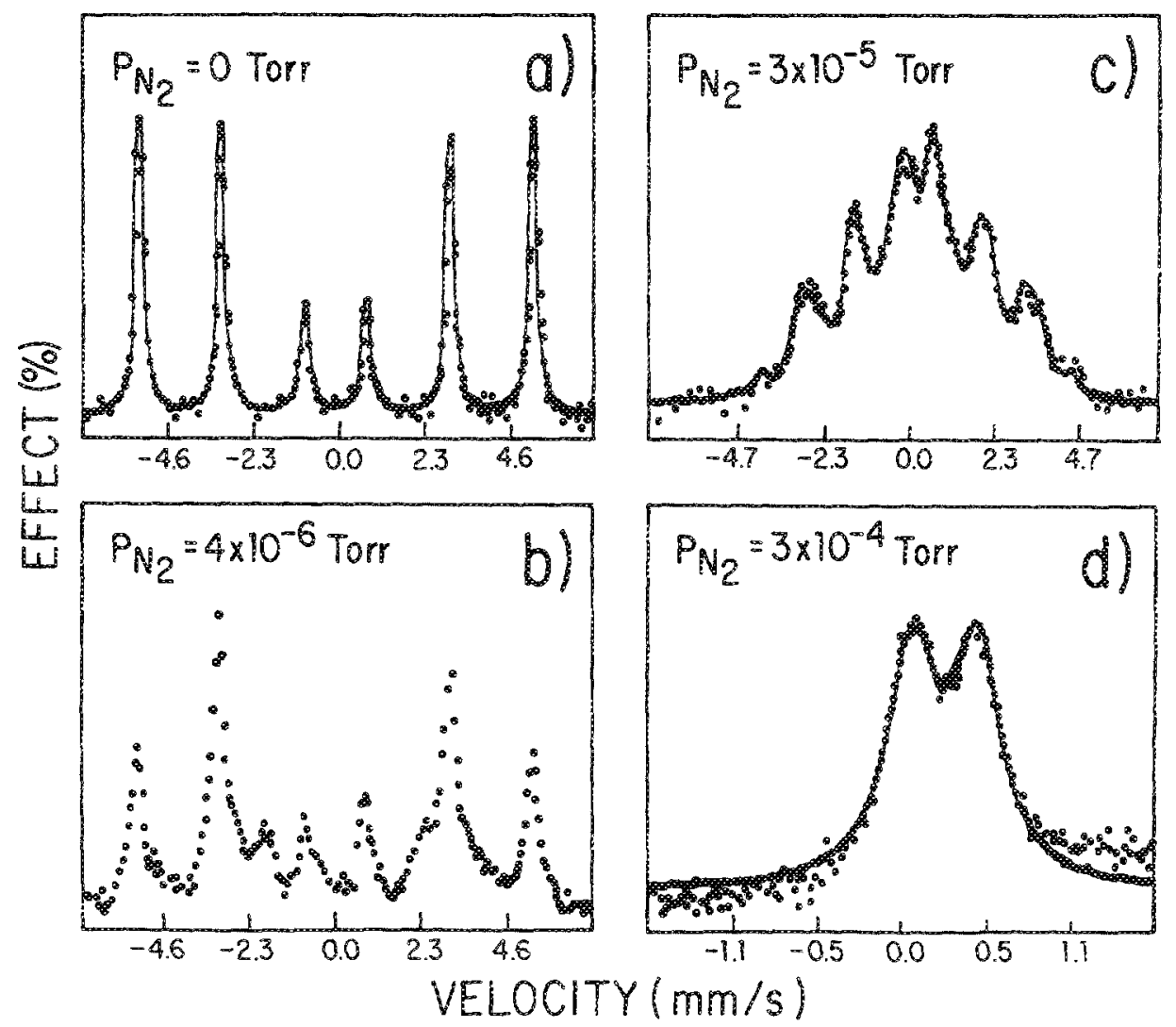

FIG. 4. Mössbauer spectra of the samples prepared at different $\mathrm{N}_{2}$ partial pressures. The experimental results are shown by heavy dots whereas the solid lines show the best fits.

with that of sample A (pure iron film). Figure 6 (a) shows a moderate in-plane magnetic anisotropy for sample $B$ which is not seen in Fig. $6(\mathrm{~b})$ for sample $\mathrm{C}$.

The sample $D\left(P_{\mathrm{N}_{2}}=3 \times 10^{-4}\right.$ Torr $)$, on the other hand, is paramagnetic with a very small magnetization even in magnetic fields as high as $5 \mathrm{kG}$ and sample temperatures as low as $77 \mathrm{~K}$.

\section{U. DISGUSSION AND CONCLUSIONS}

The main experimental findings of this work are sum. marized in Table II, where the x-ray, CEMS, AES, and VSM results are listed.

As expected the nitrogen content in the thin $\mathrm{Fe}_{x} \mathrm{~N}$ fims increases with the $\mathrm{N}_{2}$ partial pressure in the sputtering plasma. Furthermore the sputter-Auger results show a uniform composition of the nitrides as a function of depth. A very low contamination of oxygen and carbon was found.

A further inspection of Table III shows that the high saturation magnetization nitrides such as $F e_{8} \mathrm{~N}$ and $\mathrm{Fe}_{4} \mathrm{~N}$ are absent in this study. This salient feature has to be associated to the low temperature that usually occurs in magnetron sputtering. In contrast to these findings, Lo et al ${ }^{10}$ and Chang, Sivertsen, and $\mathbb{J u d y}^{13}$ report on the high iron content nitrides as found in rif diode sputtering deposition. As clearly reported by Lo et al. ${ }^{10}$ the high-temperature deposition process, between 200 and $1000^{\circ} \mathrm{C}$, typical of diode sputtering can lead to $\mathrm{Fe}_{8} \mathrm{~N}$ and $\mathrm{Fe}_{4} \mathrm{~N}$. In the present work the high deposition rate is performed using mean deposition temperatures below $60^{\circ} \mathrm{C}$. This low temperature is due to the trapping of primary and secondary electrons in the magnetic field of the magnetron, who therefore cannot bombard and

TABLE II. Mössbauer parameters of the different components used to fit the CEMS spectra. The isomer shifts are given with respect to ${ }^{57} \mathrm{Fe}$ in Rh. The samples $A, B, C$, and D were prepared in the conditions given in Table 1 .

\begin{tabular}{|c|c|c|c|c|c|c|}
\hline Sample & Identification & $H(\mathrm{kOe})$ & $\Delta E_{Q}\left(\mathrm{mms}^{-1}\right)$ & $\delta\left(\mathrm{mms}^{-1}\right)$ & $\Gamma\left(\mathrm{mms}^{-1}\right)$ & $x^{2}$ \\
\hline A & $\alpha-\mathrm{Fe}$ & 330 & $\cdots$ & 0 & 0.25 & 0.71 \\
\hline$B$ & $\begin{array}{c}\alpha-F e \\
(?)\end{array}$ & $\begin{array}{l}330 \\
\ldots\end{array}$ & $\begin{array}{l}\cdots \\
\cdots\end{array}$ & 0 & $\begin{array}{c}0.25 \\
\ldots\end{array}$ & $\begin{array}{l}\cdots \\
\cdots\end{array}$ \\
\hline C & $\mathrm{Fe}_{2+x} \mathrm{~N}$ & $\begin{array}{c}265 \\
207 \\
179 \\
78 \\
\ldots \\
\ldots\end{array}$ & $\begin{array}{c}\ldots \\
\ldots \\
\cdots \\
\cdots \\
1.00 \\
0.50\end{array}$ & $\begin{array}{l}0.37 \\
0.34 \\
0.31 \\
0.30 \\
0.37 \\
0.41\end{array}$ & $\begin{array}{l}0.47 \\
0.48 \\
0.42 \\
0.68 \\
1.46 \\
0.35\end{array}$ & 0.96 \\
\hline $\mathrm{D}$ & $\underset{\gamma \text {-austenite }}{\mathrm{Fe}_{2} \mathrm{~N}}$ & $\begin{array}{l}\cdots \\
\cdots\end{array}$ & $\begin{array}{l}0.25 \\
0.29\end{array}$ & $\begin{array}{c}0.44 \\
0\end{array}$ & $\begin{array}{l}0.49 \\
0.30\end{array}$ & 1.75 \\
\hline
\end{tabular}




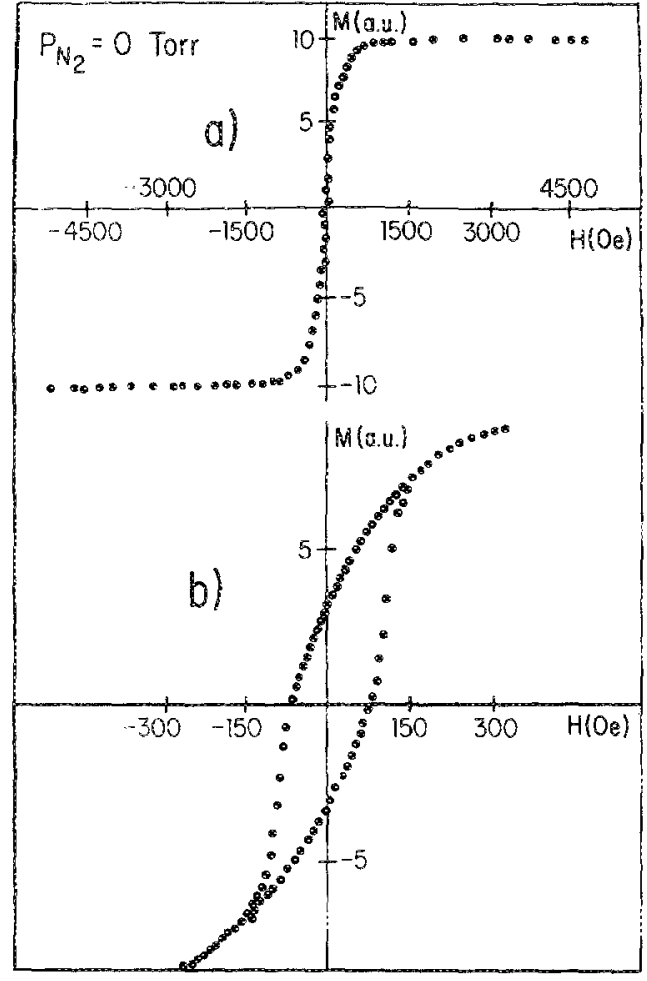

FIG. 5. In-piane hysteresis loops of sample A (pure iron film); (a) saturation magnetization; (b) detail of the internal part of the hysteresis loop. The magnetizations are quoted here in arbitrary units (a.u.).

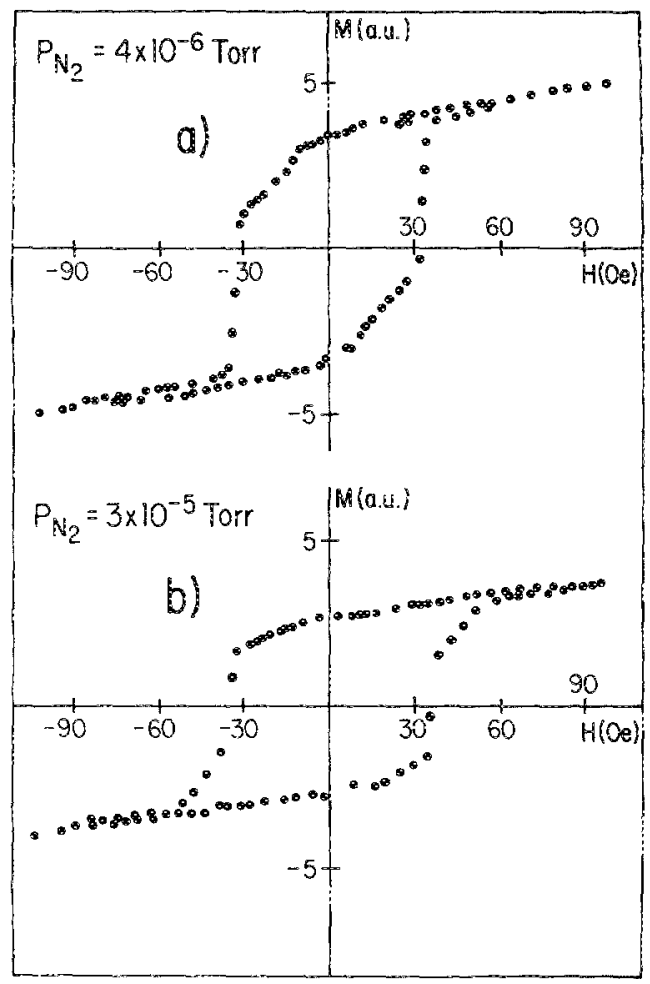

FIG. 6. In-plane magnetization as a function of the magnetic field; (a) sample $B\left(P_{\mathrm{N}}=4 \times 10^{-6}\right.$ Torr $)$ and $(\mathrm{b})$ sample $C\left(P_{\mathrm{N}}:=3 \times 10^{-6}\right.$ Torr $)$. The magnetizations are quoted here in arbitrary units (a.u.).
TABLE II. Summary of the results obtained in the analyses of the Fe-N films by different techniques. In the vibrating sample magnetometer results column we identified the ferromagnetic samples by FM and the paramagnetic samples by PARAM.

\begin{tabular}{|c|c|c|c|c|}
\hline Sample & $X$ ray & CEMS & AES & VSM \\
\hline $\begin{array}{c}\text { A } \\
P_{\mathrm{N}_{2}}=0 \text { Torr }\end{array}$ & $\alpha-F e$ & $\alpha-\mathrm{Fe}$ & & $F M$ \\
\hline$P_{N_{3}}=4 \times 10^{-6}$ Torr & $\begin{array}{l}\xi-\mathrm{Fe}_{2} \mathrm{~N} \\
\left(\mathrm{Fe}_{2} \mathrm{~N}-\mathrm{Fe}_{3} \mathrm{~N}\right)\end{array}$ & $\begin{array}{c}\alpha-\mathrm{Fe} \\
(?)\end{array}$ & $\mathrm{Fe}_{9,81} \mathrm{~N}$ & $\mathrm{FM}$ \\
\hline$P_{\mathrm{N}_{2}}=3 \times 10^{-5}$ Torr & $\begin{array}{l}\zeta-\mathrm{Fe}_{2} \mathrm{~N} \\
\varepsilon=\mathrm{Fe}_{3} \mathrm{~N}\end{array}$ & $\begin{array}{c}\mathrm{Fe}_{2} \mathrm{~N} \\
\mathrm{Fe}_{2+x} \mathrm{~N}\end{array}$ & $F e_{3.49} \mathrm{~N}$ & $\mathbb{F M}$ \\
\hline $\mathbb{P}_{N_{2}}=3 \times 10^{-4}$ Torr & $\begin{array}{l}\xi-\mathrm{Fe}_{2} \mathrm{~N} \\
\varepsilon-\mathrm{Fe}_{3} \mathrm{~N}\end{array}$ & $\begin{array}{l}\varepsilon-\mathrm{Fe}_{2} \mathrm{~N} \\
\xi-\mathrm{Fe}_{2} \mathrm{~N}\end{array}$ & $\mathrm{Fe}_{1.97} \mathrm{~N}$ & PARAM \\
\hline
\end{tabular}

heat the growing film. Thus, from the point of view of magnetic properties, the results suggest that the dc reactive magnetron sputtering leads to $\mathrm{Fe}-\mathrm{N}$ films with small saturation magnetizations (compared to pure iron films) due to presence of the paramagnetic $\mathrm{Fe}_{2} \mathrm{~N}$ phase and moderate coercivi. ties with a moderate in-plane magnetic anisotropy. The low deposition temperatures preclude the formation of Fe-rich compounds mainly because the compounds of the $\mathrm{Fe}-\mathrm{N}$ system with lower $\mathrm{Fe}$ content are preferentially nucleated at temperatures around room temperature, as it has been largely demonstrated before. ${ }^{4-8}$ Furthermore, the thermal annealing of these low-Fe phases of the films of this work (which is presently being accomplished) shows the decomposition of the low-Fe phases and the precipitation of the Ferich, $\mathrm{Fe}_{4} \mathrm{~N}$, and $\mathrm{Fe}_{8} \mathrm{~N}$ phases. It must be emphasized that despite the $\mathrm{Fe}_{8} \mathrm{~N}$ composition found for sample $\mathrm{B}$ with the Auger analysis the magnetic $\mathrm{Fe}_{8} \mathrm{~N}$ phase was not identified by the other techniques.

Another feature which is also due to the low substrate temperature during deposition is the appreciabie phase inhomogeneity which is present in samples $B$ and $C$. This mixture leads to very complicated $x$-ray and CEMS spectra. Even the relatively "simple" sampie D (which was obtained by pure nitrogen plasma sputtering) shows the $\mathrm{Fe}_{2} \mathrm{~N}$ compounds together with the randomic occupation of the interstitial sites by nitrogen atoms, as revealed by $\mathrm{x}$-ray and CEMS analyses.

This work will continue in two ways. We are analyzing the post-deposition thermal treatment evolution of the samples looking for phase stabilities and phase transformations of the nitrides. Second we want to test the ideas of Naoe, Nagakubo, and Yamamoto ${ }^{23}$ who performed ion-beam-assisted deposition (IBAD) of $\mathrm{Fe} / \mathrm{Fe}_{x} \mathrm{~N}$ multilayers. It would be interesting to see if these soft magnetic multilayers are feasible using the magnetron sputtering technique.

\section{ACKNOWLEDGAENTS}

We thank Paulo G. Cunha, Jr. and B. A. S. de Barros, Jr. for síkillful technical assistance and for many fruitful discussions. We would also like to thank $D r$. J. Schaf for support in the magnetic measurements. This work was supported in part by Conselho Nacional de Desenvolvimento Cientifico e Tecnológico ( $\mathrm{CNPq}$, Brasil). 
${ }^{1}$ M. Mekata, H. Yoshimura, and Hi. Takaki, J. Phys. Soc. Jpn. 33, 62 (1972).

${ }^{2}$ T. Ysmaoka, M. Mekata, and H. Takaki, J. Phys. Soc. Jpn. 35, 63 (1973).

${ }^{3}$ T. Moriya, Y. Sumitomo, H. Ino, F. E. Fujita, and Y. Maeda, J. Phys. Soc. Jpn. 35, 1378 (1973).

${ }^{4}$ N. DeCristofaro and R. Karplow, Metall. Trans. A 8, 425 (1977).

${ }^{5}$ N. DeCristofaro and R. Karplow, Metall. Trans. A 8, 35 (1977).

'R. Frattini, G. Princini, B. Tiveron, and C. Toseilo, J. Mater. Sci. 17, 1683 (1982).

${ }^{7}$ C. A. dos Santos, B. A. S. de Barros, Jr., J. P. de Souza, and I. J. R. Baumvol, Appl. Phys. Lett. 11, 237 (1982).

${ }^{8}$ C. A. dos Sanios, M. Behar, and I. J. R. Baumvol, J. Phys. D 17, 551 (1984).

${ }^{9}$ C. Lo, S. V. Krishnaswamy, R. Messier, K. R. R. M. Rao, and I.. N. Mulay, J. Vac. Sci. Technol. 18, 313 (1981).

${ }^{10} \mathrm{C}$. Lo, \$. V. Krishnaswamy, L. N. Mulay, and R. A. Difenbach, J. Appl. Phys. 53, 2745 (1982).

'N. Terada, Y. Hoshi, M. Naoe, and S. Yamanaka, IEEE Trans. Magn. MAG-20, 1451 (1984).

Z. Umeda, E. Kita, and A. Tasaki, IEEE Trans. Magn. MAG-22, 591 (1986).
${ }^{13} \mathrm{C}$. Chang, 3. M. Silvertsen, and J. H. Judy, JEEE Truns. Magzh. MAG-23. 3636 (1987)

${ }^{14}$ M. Kume, T. Tsujika, K. Matsuura, Y. Abe, and A. Tasuky, IEEE Trans. Magn. MAG-23, 3633 (1987)

${ }^{15}$ M. Nagakubo, T. Yamamoto, and M. Naoe, J. Appl. Phys. 63,4309 (1988).

'6M. Kume, S. Takahashi, T. Tsujioka, K. Matsuura, and Y. Abe, IEEE Trans. Magn. MAG-24, 3003 (1988).

17M. Asano, K. Umeda, E. Kita, and A. Tasaki, LEEE Trans. Magn. MAG. 24, 2997 (1988)

${ }^{18}$ S. R. Teixeira, C. A. dos \$antos, P. H. Dionisio, W. H. Sohreiner, and I. J. R. Baumvol, Mater. Sei. Eng. 96, 285 (1987)

${ }^{19}$ S. R. Teizeira, F. L. Freire, and I. J. R. Raumvol. Appl. Phys. A 68,481 (1989).

${ }^{20} \mathrm{G}$. Longworth and R. Ackinson, Adv. Chem. Ser. 194, 101 (\$981).

${ }^{2}$ O. Kubaschewski, Iron-Binary Phase Diagrams (Springer, New York, 1982), p. 67.

${ }^{22}$ M. Chabanel, C. Janot, and J. P. Mote, C. R. Acad. Sci. Paris B 226, 419 (1968).

${ }^{23}$ M. Naoe, M. Nagakubo, and T. Yamamoto, J. Appl. Phys. 64,5449 (1988). 